\title{
IMPORTÂNCIA DE INCUBADORAS DE EMPRESAS EM AMBIENTE ACADÊMICO: UM ESTUDO DO PERFIL EMPREENDEDOR DOS DISCENTES
}

\author{
R. M. MICHELY, L. C. SILVA, R. L. S. GIUDI
}

\section{RESUMO}

O empreendedorismo está em constante crescimento no Brasil, o que contribui consideravelmente para o desenvolvimento do país. Dessa forma, instituições de ensino e órgãos governamentais promovem ações para o desenvolvimento do perfil empreendedor dos indivíduos, com o intuito de promover uma prática empreendedora na atualidade e induzir práticas futuras. O presente trabalho tem por objetivo analisar o perfil empreendedor dos alunos do Instituto Federal de Educação, Ciência e Tecnologia do Rio Grande do Norte, campus São Gonçalo do Amarante, a fim de verificar se o campus necessita da implantação de uma incubadora de empresas. A pesquisa trata-se de um estudo de caso com abordagem quantitativa de caráter exploratório, realizado a partir de revisão da literatura. A pesquisa de campo será feita por meio de questionários estruturados, a fim de identificar o perfil empreendedor dos alunos dos cursos de Redes de computadores, Informática, Edificações e Logística do IFRN São Gonçalo do Amarante, nas modalidades de Ensino Médio Integrado, Subsequente e Graduação. A partir dos dados coletados, observou-se que a maior parte dos alunos apresentam o perfil empreendedor em desenvolvimento, o que salienta a importância da instalação da incubadora de empresas no campus IFRN/SGA.

Palavras-Chaves: Inovação Tecnológica, Empreendedorismo, Incubadora de empresas, Capacidade Empreendedora.

\section{ABSTRACT}

Entrepreneurship is constantly growing in Brazil, this contributes considerably to the development of the country. Thus, educational institutions and government agencies promote actions to develop the entrepreneurial profile of individuals, in order to promote an entrepreneurial practice in the present and to induce future practices. The objective of this study is to analyze the entrepreneurial profile of the students of the Federal Institute of Education, Science and Technology of Rio Grande do Norte, Campus São Gonçalo do Amarante, aiming to reinforce the need to implement a business incubator on campus. The research is a case study with a quantitative approach of exploratory character, carried out from a literature review. Field research will be done through structured questionnaires in order to identify the entrepreneurial profile of the students of the Computer Networking, Computing, Buildings and Logistics courses of IFRN São Gonçalo do Amarante, in the modalities of Integrated Secondary Education, Subsequent and Graduation. From the data collected, it was observed that most of the students present the entrepreneurial profile under development, which highlights the importance of the incubation of companies in the IFRN/ SGA campus.

Keywords: Technology innovation, Entrepreneurship, Business Incubator, Entrepreneurial Capability. 


\section{INTRODUÇÃO}

Com passar dos anos, o mercado vem se tornando mais competitivo e estratégico ao ponto de se inovar constantemente. Assim, o termo empreendedorismo vem ganhando destaque, sendo reconhecido como um dos principais fatores do desenvolvimento socioeconômico no mundo. O empreendedorismo facilita na criação, desenvolvimento e melhoria de produtos/serviços, pois necessita de uma série de atividades, tais como o reconhecimento de oportunidades, aprimoramento de conceitos de negócios, criatividade para inovar e otimização de recursos (WANG, 2016).

Atrelado ao movimento empreendedor, a inovação tem papel fundamental no estímulo dos indivíduos, uma vez que aprimora a capacidade de investir e incrementar práticas empreendedoras. Essas atividades inovadoras geram resultados satisfatórios para a região, em termo de desenvolvimento socioeconômico, assim gerando novos postos de trabalho, maior qualidade de vida e impulsionando o crescimento econômico da cidade.

Levando em consideração estes aspectos o empreendedorismo vem sendo explorado também nas instituições de ensino, principalmente nas de ensino superior que enxerga a necessidade de capacitar e motivar os discentes para iniciativas empreendedoras que gerem emprego e desenvolvimento econômico para sociedade.

No Brasil, existe uma alta taxa de mortalidade das empresas que estão iniciando no mercado. De acordo com o SEBRAE (2016), as microempresas apresentam maior taxa de mortalidade pelo grande número de empresas desse porte no mercado. Em comparação, já as empresas de pequeno porte, médias empresas e grandes empresas conseguem se manter no mercado por apresentarem estrutura definida e maior capital de investimento. Assim sendo, as incubadoras de empresas auxiliam promovendo auxilio administrativo e estrutural para as microempresas, construindo assim capacidade de desenvolver suas ideias a fim de estruturá-las para o mercado. A principal função da incubadora é criar o ambiente propício e facilitar os recursos necessários para fazer um negócio crescer rapidamente (FÉLIX; GUTIÉRREZ; BURBOA, 2013).

As incubadoras de empresas permitem aos empreendedores, desenvolver a inovação tecnológica, que auxiliará na solução dos problemas cotidianos da sociedade, como por exemplo, a criação de uma empresa de aplicativos urbanos. As incubadoras promovem o incentivo a inovação tornando-os estratégicos.

A identificação do potencial empreendedor dos discentes possibilita a facilidade do ensino deste tema, podendo dar uma dinâmica diferenciada aos diferentes graus de ensino, facilitando também a exploração dos potenciais e as ideias empreendedoras de cada indivíduo. Desta feita, o objetivo deste estudo é analisar o perfil empreendedor dos alunos da Instituição Federal do Rio Grande do Norte Campus São Gonçalo do Amarante a fim de salientar a importância de se implantar uma incubadora no campus. Verificou-se também que não foram encontrados pesquisas que abordem este tipo de tema, dessa forma a realização da seguinte pesquisa foi executada de maneira que interligará os conceitos abordados pela literatura com as informações obtidas no IFRN São Gonçalo do Amarante. 


\section{FUNDAMENTAÇÃO TEÓRICA}

\section{Empreendedorismo como fator desenvolvedor da sociedade}

"A palavra empreendedor (entrepreneur) é originada do francês e é utilizada para caracterizar uma pessoa que realiza coisas novas, ou seja, inova e faz acontecer" (AGUIAR; MARTINS, 2015). O empreendedorismo se destaca mostrando-se como um diferencial inovador, no qual o profissional deve apresentar capacidades de inovação, trazendo ideias para administrar as decisões que trarão sucesso para uma organização. Devece e Peris-Ortiz et al., (2016) respaldam que a chance de empreender está relacionada com novas oportunidades e inovação, como a junção de novos processos e tecnologias que incitam o interesse do empreendedor.

O empreendedor sujeito principal, caracteriza-se como pessoa fundamental, inovadora e que busca seus objetivos sem titubear, mesmo em cenários de crise. Persistência, intuição e desejos, são características importantes vistas no sujeito empreendedor. Corroborando Carland; Carland e Stewart (2015) afirmam que um empreendedor apresenta uma força inicial, enxerga oportunidades e desafios e leva esses desafios a diante.

Diante das situações econômicas novas formas de empregabilidade são fortemente encontradas, nesse sentindo surge o modelo de empregabilidade própria derivada de práticas empreendedoras, que permite o interesse pelo estudo do empreendedorismo como mais uma alternativa para geração de emprego e formação de uma classe empresarial local sólida com uma visão globalizada. Constatando, Staniewsk (2016) afirma que o empreendedorismo interessa as pessoas que querem construir sua própria renda de acordo com seu esforço próprio.

A partir da década de 1990, no Brasil, o tema empreendedorismo teve um amplo interesse nas práticas organizacionais, tendo em vista, que o crescimento de micro e pequenas empresas teve grande aumento pelo alto índice de desemprego ocorrido na época (DORNELAS, 2008). Corroborando, Aguiar e Martins (2015, p.14) Afirmam que "três a cada dez brasileiros adultos entre 18 e 64 anos possuem uma empresa ou estão envolvidos com a criação de um negócio. A taxa de empreendedorismo no país subiu de $23 \%$ para 34,5\% em dez anos".

O empreendedorismo tem se tornado um fator importante no desenvolvimento econômico e social no Brasil. O mercado, não somente brasileiro, mas mundial, tem se mostrado mais competitivo e com o passar dos anos mostra-se como fonte de inovações pertinentes a demanda, que se mostra mais atenta e exigente. Crecente-romero et al., (2016) reforça que quanto maior a diversidade da região e dos avanços da inovação, maior o número de empreendedores. Aliado as questões culturais e pessoais, o empreendedorismo no Brasil vem crescendo em maior ritmo ao longo dos anos.

Segundo dados mais recentes do relatório executivo da Global Entrepreneuship Monitor (2014), no Brasil, pouco mais de metade $(55,5 \%)$ da população percebe boas oportunidades de negócios. Apenas os Estados Unidos (50,9\%) e México (48,9\%) têm taxas parecidas. O Brasil está entre os países com as percepções mais positivas sobre as oportunidades de empreendedorismo. O relatório executivo ainda mostra um forte aumento de novos empreendedores, apresentando 13,8\% em 2014.

Como já foi dito, o Brasil possui um grande potencial em empreendedorismo, mas para que este potencial seja explorado da melhor forma é necessário que ocorra a união entre instituições educacionais, empresas e governo, isto se intitula tríplice hélice.

As instituições federais de ensino e universidades são disseminadoras de conhecimento. Através dessas organizações pesquisas são desenvolvidas, fomentando a necessidade local e nacional. A interação dessas instituições com outros meios públicos e privados, torna importante no que tange ao desenvolvimento de oportunidades e de conhecimento. Segundo Perucchi (2015) a interação das três 
vertentes da tríplice hélice possibilita a condução do conhecimento para um ambiente produtivo de forma mais rápida e eficaz.

Francisco et al., (2015) afirma que a universidade se apresenta como um caminho no processo de desenvolvimento social e seu papel na economia do conhecimento é importante. Ou seja, as instituições de ensino constituem-se como meio principal no alicerce do desenvolvimento de novos saberes.

Aliada aos conceitos anteriores, a tríplice hélice promove a interação entre universidade, empresa e governo, utilizando-se de meios esses três participantes promovem interação e ganhos a cada um.

\section{A Universidade, como promotora do conhecimento cientifico, fornece as bases para o desenvolvimento tecnológico que é utilizado pelas organizações empresariais, enquanto estas criam as bases de inovação que devem ser sustentadas pelas políticas públicas, materializando o papel do governo nesse aspecto (FRANCISCO et al., 2015, p.4).}

Verlinde e Macharis (2016) constatam que a tríplice hélice é uma referência de inovação que permite uma estrutura de múltiplas relações recíprocas entre todos os três participantes. "A configuração ideal da Hélice Tríplice é aquela em que as três esferas interagem e cada uma assume o papel das outras, sendo que as iniciativas surgem lateralmente bem como de baixo para cima e de cima para baixo" (PADULA; DA SILVA; JUNIOR, 2016, p.151).

\section{INCUBADORA DE EMPRESAS: UM HABITAT DE INOVAÇÃO}

É notório as constantes mudanças no mercado e nas organizações. Com o avanço das tecnologias os mercados estão mais competitivos e os clientes mais exigentes quanto as especificações dos produtos. A inovação tecnológica tem se mostrado presente nos dias atuais, por transparecer a necessidade atual das tecnologias.

A inovação quando se refere a empreendedorismo e incubadoras, é um conceito fundamental de trabalho. Os empreendedores e futuros gestores necessitam ter inovação em seus processos para manterse no mercado. Já as incubadoras, salientam a importância da inovação nos gestores, para o provimento de empresas mais tecnológicas e que permaneçam no mercado. Segundo Santos (2016, p.31):

\section{As grandes economias são baseadas no conhecimento. Esse fato se dápela mudança tecnológica gerada pela inovação. A sua criação é desenvolvida pelo gerenciamento das capacidades, possibilitando a potencialização da capacidade. Para a economia baseada no conbecimento, a inovação é um ponto central.}

No Brasil, a Lei 10.973/04 trata do incentivo a inovação e a pesquisa tecnológica. A lei regulamenta agências de fomento, incubadoras de empresas, inovação, núcleos de inovação tecnológica, polos tecnológicos, capital intelectual etc.

O movimento das incubadoras de empresas vem se destacando no cenário social e trabalhista nos últimos anos. A estrutura que a incubadora possibilita aos empreendedores, torna as ideias e inovações mais estruturadas e possíveis de acontecer pois sabe-se que a fase inicial, ou seja, o nascimento da ideia é onde deve-se maior cautela, devido a imaturidade de seu propósito ou falta de infraestrutura. De acordo com Andrade (2016, p.59):

Na década de 1980, no Brasil, as incubadoras começaram a ser criadas por meio de uma inciativa do Conselho Nacional de Desenvolvimento Científico e Tecnológico (CNPq), a partir da implantação do primeiro Programa de Parques Tecnológicos no País. Essa iniciativa desencadeou ações voltadas ao empreendedorismo inovador em território brasileiro. 
Mas-Verdú et al. (2015) afirmam que as incubadoras produzem empresas bem-sucedidas que consequentemente saem do processo de incubação prontas para o mercado. Os autores ainda auxiliam a afirmação contestando que as incubadoras estimulam a inovação e o desenvolvimento regional.

As incubadoras de empresas, se tornam essenciais não apenas ao crescimento de uma empresa e da ideia empreendedora, mas se torna um caminho alternativo para o crescimento de geração de emprego e movimentação econômica do país. A incubadora permite amadurecer ideias empreendedoras e dar suporte a suas estratégias e estruturas, a fim de proporcionar o desenvolvimento da mesma e salientar a sua importância para a sociedade. Stokan, Thompson e Mahu (2015) alegam que as incubadoras promovem maior assistência a empresas jovens, possibilitando maior facilidade no crescimento empresarial.

O conhecimento das etapas da incubação é essencial para que o empreendedor possa entender como acontece seu funcionamento e preparar-se para possíveis processos seletivos de entrada. As etapas de uma incubadora de empresa dividem-se como mostra a Figura 1:

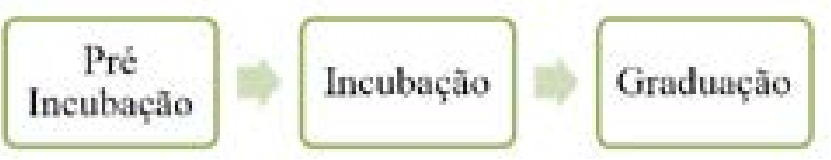

Figura r: Etapas da incubadora de empresas. Fonte: Autor (2017).

As incubadoras apresentam três etapas de acompanhamento das empresas: 1) A pré- incubação: nasce a ideia inicial da empresa. É nessa fase onde a ideia inicial ainda precisa ser modelada a fim e de encontrar o objetivo claro da ideia de negócio; 2) Incubação: a empresa está se formando, capacitando os colaboradores e a ideia já está formalizada. Nessa fase a empresa já está participando de treinamentos e vivenciando sua ideia no dia a dia; 3) Graduação: a empresa não reside mais na incubadora e passa a instalar-se sozinha no mercado. Dessa forma, a empresa passa a viver por conta própria com todos os conhecimentos adquiridos durante os anos instalados na incubadora de empresas. Martelo, Claro e Vieira (2016) corroboram que as incubadoras possuem equipes experientes com foco nos resultados, participação nos modelos de negócios e indução ao desenvolvimento de pesquisas dos empreendimentos instalados.

É evidente que as incubadoras trazem diversos resultados nas instituições de ensino, diante do mercado crescente e tecnológico, as incubadoras desenvolvem nos discentes dos institutos e universidades benefícios como a qualificação correta dos futuros gestores beneficiando o desenvolvimento local e tecnológico. Segundo Pereira et al., (2015) outro fator importante adquirido pelas empresas incubadas, é que as incubadoras agem como instrumento de contato para que as empresas incubadas consigam captação de fomentos, auxiliando na captação de novos mercados.

Ribeiro (2016) alega que a incubadora auxilia nas falhas do mercado gerando empregabilidade, renda e impostos. Quanto a comunidade local promove a cultura empreendedora e autoestima dos moradores, consequentemente elevando a renda local. Corroborando, Wonglimpiyarat (2016) afirma que as incubadoras são mecanismos que impulsionam o desenvolvimento local e reduz as falhas de pequenas empresas iniciais.

É certo afirmar também que a incubadora permite fornecer aos empreendedores vantagens como: espaço físico adequado, onde as empresas incubadas podem usufruir de rede telefônica e de internet por preços acessíveis, qualificação e assessoria no planejamento de suas ideias de negócios, possibilidade de aumento da rede de networking e acompanhamento da incubadora com os projetos incubados. "Elas também procuram maximizar o potencial de agência empreendedora provendo as incubadas com serviços e suporte que complementam seus talentos e recursos, capacitando-as a expandir seu potencial" (PEREIRA et al., 2015, p.111). 


\section{METODOLOGIA DA PESQUISA}

A presente pesquisa se caracteriza como exploratória, que conforme Kauark, Manhães, Medeiros (2010, p. 29) "objetiva a maior familiaridade com o problema, tornando-o explícito, ou à construção de hipóteses". Assim sendo, o presente estudo constituiu-se de um estudo de caso, na qual fez-se uma pesquisa de campo, a fim de identificar o perfil empreendedor dos alunos do Instituto Federal, campus São Gonçalo do Amarante/RN.

Quanto ao procedimento técnico, a pesquisa se enquadra como estudo de caso que conforme Gil (2002) consiste no estudo profundo dos objetos, visando uma compreensão mais clara do assunto em questão. Corroborando, Yin (2001) ressalta ou destaca que o estudo de caso examina um contexto dentro da vida real, principalmente para explicitar o que não está muito claro na pesquisa. Dessa maneira apresenta-se, a seguir, as etapas da pesquisa conforme a Figura 2.

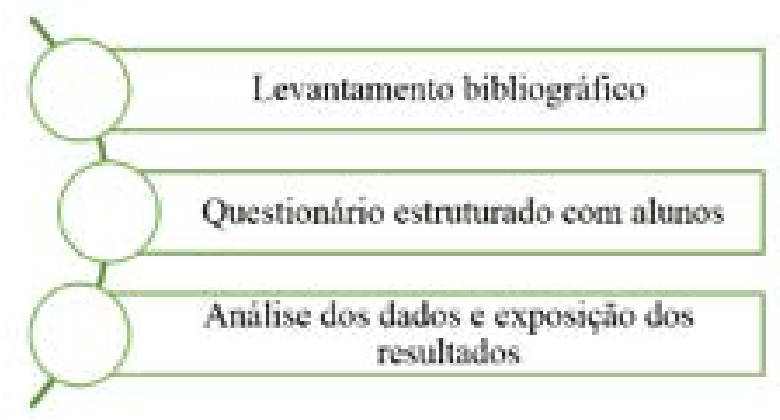

Figura 2: Etapas da pesquisa. Fonte: Autor (2017).

Observa-se da Figura 2 que o estudo se constitui em três etapas. Inicialmente, foi realizado o aprofundamento teórico com os conceitos mais atuais sobre os temas abordados nesta pesquisa, posteriormente os esforços foram centrados na utilização e adequação do questionário estruturado com os alunos, por fim, analisou-se os dados para a exposição dos resultados finais.

Como instrumento de pesquisa utilizou-se o questionário por entender que uma melhor compreensão dos objetivos da pesquisa seja alcançada Gil (2002). O questionário criado por Dornelas contém 30 questões com escalas de 1 (Insuficiente), 2 (Fraco), 3 (Regular), 4 (bom) e 5 (Excelente) e classifica 4 tipos de perfis empreendedores: (1) Perfil empreendedor nato-PE: já possui características empreendedoras; (2) Perfil empreendedor em desenvolvimento- PED: este perfil já possui características empreendedoras, mas precisa desenvolver melhor os pontos fracos; (3) Perfil empreendedor administrador-PA: possui características de um administrador tradicional, não apresentando atitudes empreendedoras e (4) Não empreendedor-NE: não apresenta nenhum comportamento empreendedor.

O questionário aplicado teve pequenas alterações quanto a linguagem das perguntas, uma vez que a maioria dos alunos que responderam os questionários poderiam ter dificuldades com palavras mais complexas, por isto, deixou-se o questionário mais simples, porém sem alterar suas perguntas e finalidade.

Dessa forma, o instrumento de pesquisa foi aplicado na totalidade das turmas dos cursos técnicos na modalidade integrado presentes no IFRN, Campus São Gonçalo do Amarante, que englobam: Logística, Edificações e Informática, nos turnos da manhã e da tarde, bem como foi aplicado nos cursos superiores de Logística e Redes de computadores, nos turnos manhã, tarde e noite. A princípio aplicou-se um teste piloto com três alunos de diferentes turmas a fim de perceber e analisar a existência de alguma dificuldade no entendimento dos questionários. Após essa etapa, realizou-se o levantamento de dados, tendo sido aplicados 568 questionários. 
É importante salientar que do total de 568 questionários, 11 tiveram que ser descartados por alguns não terem sido respondidos corretamente ou não terem sido respondidos, o que totalizou em 557 questionários respondidos. O instituto tem um total de 953 alunos matriculados, referente ao período de 2016.2, informação esta retirada do relatório de alunos matriculados no dia 08/02/2017, disponível no sistema interno do campus.

Com as informações retiradas do sistema interno, pode se perceber o número de alunos total por modalidade. A modalidade integrado consta no sistema que existem 610 alunos matriculados, mas foram aplicados 375 questionários. $\mathrm{Na}$ modalidade subsequente o total de alunos constatado foram de 140 discentes, porém foram aplicados 81 questionários. Já na modalidade graduação, o total de alunos foram de 171 alunos matriculados, mas na aplicação dos questionários, apenas 101 discentes responderam. É notório que o valor total de alunos diverge do número que questionários aplicados, pois, quando aplicado alguns alunos faltaram ou não estavam frequentando regularmente as aulas.

\section{DISCUSSÃO DOS RESULTADOS}

A partir das análises dos resultados dos questionários aplicados, pode se fazer conclusões acerca dos aspectos analisados. Na primeira análise observou-se os resultados do perfil empreendedor de cada modalidade de curso. Percebe-se que foi constatado um único perfil comum a todas as turmas, como mostra a Figura 3:

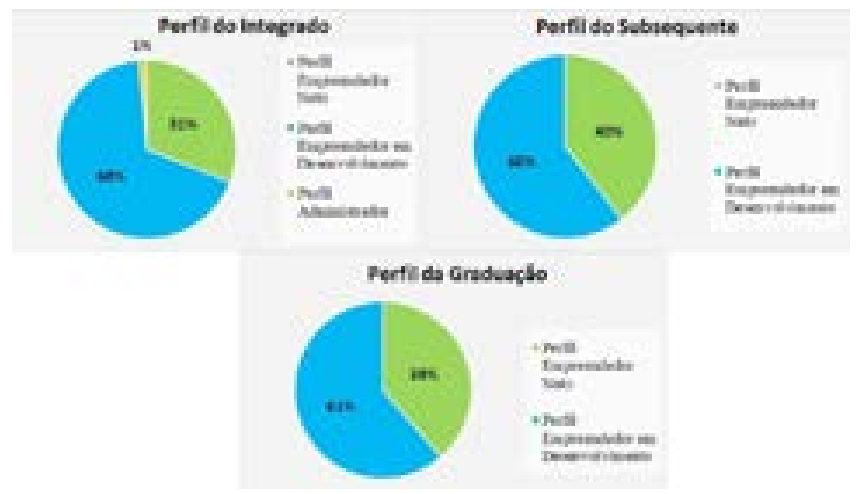

Figura 3: Perfis empreendedores das modalidades de cursos.

Fonte: Pesquisa direta(2017).

A partir das análises dos perfis das modalidades de cursos, pode-se concluir que as modalidades do integrado, subsequente e graduação obtiveram o mesmo resultado de perfil, enquadrando-se no perfil empreendedor em desenvolvimento-PED, o que segundo Dornelas (2008) é um tipo de perfil que é tido como conhecedor do empreendedorismo, mas que ainda apresenta dificuldades em melhorar seus pontos fracos, para assim, tornar-se um empreendedor nato. Este resultado é oriundo do ensino do instituto que permite aos alunos a participação em pesquisas, extensões e projetos integradores que proporciona aos discentes o contato com práticas e pensamentos empreendedores, o que é ressaltado por Francisco et al., (2015) que afirma que a universidade se apresenta como um caminho no processo de desenvolvimento social e seu papel na economia do conhecimento é importante.

Outra análise realizada é a do perfil empreendedor dos cursos. Percebe-se com base nos dados que o perfil empreendedor em desenvolvimento- PED, como mostra a Figura 4: 


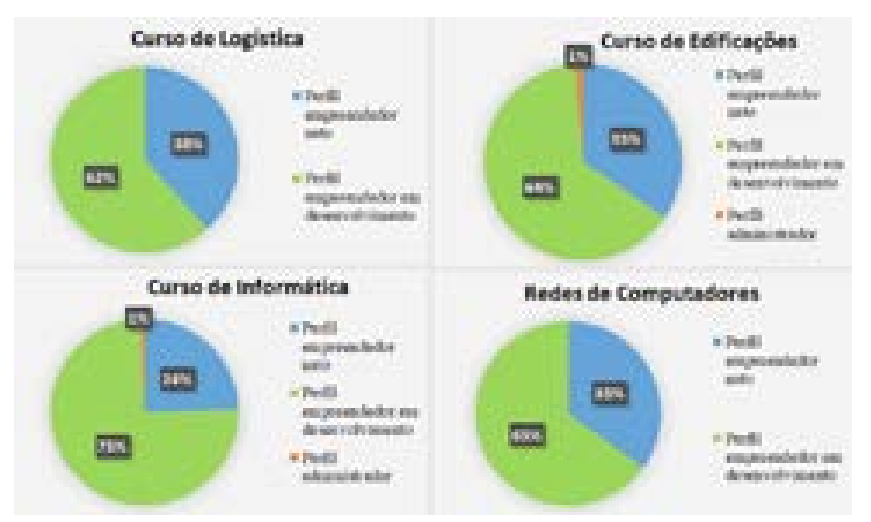

Figura 4: Perfis empreendedores dos cursos.

Fonte: Pesquisa direta (2017).

A partir da análise dos dados, percebe-se que o perfil empreendedor em desenvolvimento teve maior destaque nos três cursos do campus. Nota-se que o curso de Informática teve uma maior porcentagem do perfil, o que pode estar relacionado ao desejo dos alunos de serem empreendedores do ramo da tecnologia, o que atualmente é visto como um ramo que cresce e se desenvolve constantemente. Os cursos de Logística, Edificações e Redes de computadores apresentaram porcentagens com poucas diferenças, o que infere-se que os discentes também possuem capacidade de empreender, visto que possuem, assim como o curso de informática, nas suas grades curriculares disciplinas e atividades que incitam a busca pelo conhecimento e interesses as práticas do empreendedorismo, o que contribui com o que Devece e Peris-Ortiz et al., (2016) afirmam que a chance de empreender está relacionada com novas oportunidades e inovação, como a junção de novos processos e tecnologias que incitam o interesse do empreendedor.

Em seguida, analisou-se o perfil empreendedor dos sexos feminino e masculino dos discentes do campus. A partir da Figura 5, analisou-se o perfil empreendedor feminino, onde teve como destaque o perfil empreendedor em desenvolvimento.

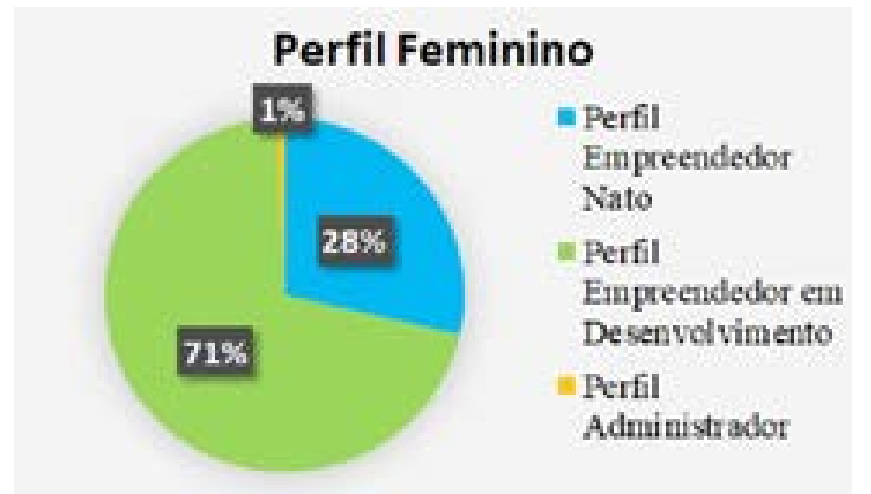

Figura 5: Perfil empreendedor feminino. Fonte: Pesquisa direta (2017)

Da figura 5, percebe-se que o perfil empreendedor em desenvolvimento foi destaque com $71 \%$. A partir do gráfico exposto, pode-se inferir que as mulheres tem buscado cada vez mais conhecimento sobre o empreendedorismo justificando, possivelmente, o alto número de mulheres com perfil empreendedor em desenvolvimento nessa pesquisa o que também resultou na porcentagem baixa no perfil empreendedor nato, ou seja, apesar de não crescerem com hábitos empreendedores, as mulheres estão buscando conhecimentos em empreendedorismo. É notório o crescimento da atuação das mulheres no empreendedorismo, visto que elas têm buscado uma maior independência financeira em um negócio próprio. Atualmente, é comum mulheres conquistarem sucesso como empreendedoras, como pode ser visto em meios de comunicação, a busca por igualdade de salário e o avanço da facilidade da tecnologia induz as mulheres a buscarem o empreendedorismo. 
É necessário ressaltar que é importante conhecer melhor as práticas empreendedoras para contribuir com o aperfeiçoamento futuro do perfil empreendedor nato, o que pode ser configurado, através de palestras, mini cursos ou até testes de perfil empreendedor, que possibilitará um aperfeiçoamento das características empreendedoras e com o auxílio das incubadoras podem melhorar seu perfil e dificuldades, o que ressalta Martelo, Claro e Vieira (2016) as incubadoras possuem equipes experientes com foco nos resultados, participação nos modelos de negócios e indução ao desenvolvimento de pesquisas dos empreendimentos instalados, assim permitindo evolução e desenvolvimento também dos empreendedores.

Em consonância, a análise feita sobre o perfil empreendedor masculino, também foi constatado um maior percentual do perfil empreendedor em desenvolvimento, como explana a figura 6:

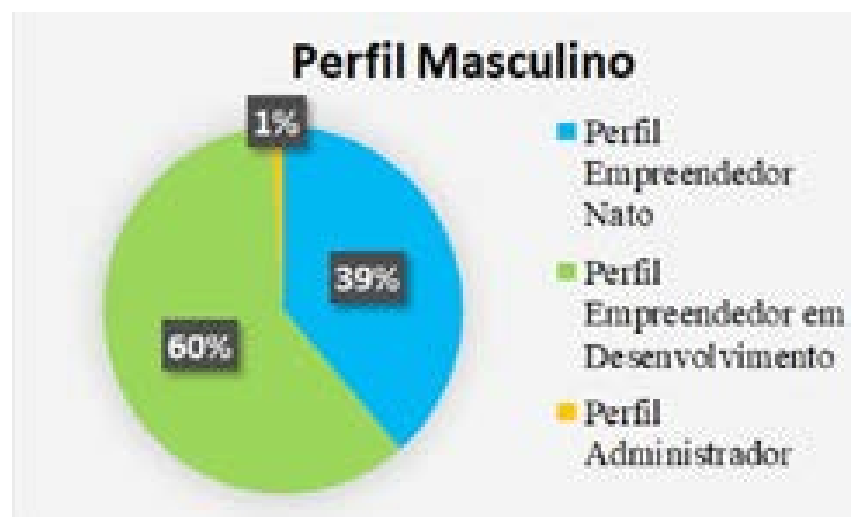

Figura 6: Perfil empreendedor masculino Fonte: Pesquisa direta (2017).

Operfilmasculinoapresentou resultadosexpressivoscomoperfilempreendedorem desenvolvimento. É importante salientar, que o perfil masculino também apresenta resultados significativos que mostram a busca pelo empreendedorismo como fonte de renda, através de ideias de negócios. Estes resultados só alicerçam a importância do aprofundamento nos conhecimentos em empreendedorismo, para que os pontos fracos sejam melhorados para em seguida ir ao próximo passo que é ser um empreendedor nato. Em comparação com o sexo feminino, o masculino mostrou menor perfil empreendedor em desenvolvimento e maior perfil empreendedor nato o que ressalta que os homens já são estimulados a serem empreendedores desde cedo e as mulheres atualmente procuram aprender mais sobre as práticas empreendedoras.

A última análise observada, fez relações entre as escalas de idades e o perfil empreendedor de cada uma. Na Tabela 1 mostra as respectivas escalas, os perfis empreendedores e as porcentagens de cada, o que resultou em um destaque nas maiores notas, resultando no perfil da idade.

\begin{tabular}{|c|c|c|c|c|}
\hline Weater neta & 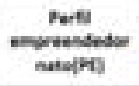 & 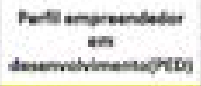 & Note & Who \\
\hline$\$ 5017$ & 2425 & $\operatorname{sen}$ & cost & 2000 \\
\hline 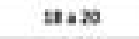 & w35 & at:an & 2.45s & a.ses \\
\hline $2 t \cdot 2 s$ & $32 \sec$ & Whes & $\cos x$ & and \\
\hline 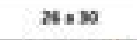 & sus & $7 s, 000$ & soos & $900 \mathrm{~N}$ \\
\hline Aolne de 50 & se.ses & so,oen & e.cos & a,oes: \\
\hline
\end{tabular}

Tabela r: Escalas de idades e perfil empreendedor

Percebe-se com os resultados do quadro 1 que as escalas de idade, com exceção da faixa etária acima de 30 que obteve 50\% perfil empreendedor (PE), o perfil em desenvolvimento (PED) obteve maior destaque. É importante salientar que o perfil PED é tido como um bom perfil, pois, já é considerado um quase empreendedor o que segundo Dornelas (2008) se não fosse pela falta de equilíbrio dos pontos fracos, para unir-se aos pontos fortes que já possui, já seria classificado como empreendedor nato.

Analisando os resultados, as porcentagens que mais chamam atenção são as compreendidas entre a faixa etária de 26 a 30, que obtiveram resultado maior de 73,08\% com o perfil PED, o que infere que 
pelo fato de serem pessoas que já trabalham, são mais maduras e são chefes de família, são induzidas a procurar informações sobre empreendedorismo, para futuramente abrirem seus próprios negócios a fim de buscar a realização profissional e uma maior renda.

Outra faixa etária que chama atenção, é a de acima de 30 anos que obteve resultados iguais no PE e no PED, o que salienta que as pessoas mais maduras procuram empreender mas ao mesmo tempo precisam se aperfeiçoar e buscar conhecimentos pelo empreendedorismo, o que possibilitaria às pessoas do perfil PED uma capacidade empreendedora igual as do PE.

\section{CONSIDERAÇÕES FINAIS}

A partir desta pesquisa, foi possível analisar vários aspectos importantes em relação ao perfil empreendedor dos discentes do instituto federal campus São Gonçalo do Amarante. Os estudos feitos nesta pesquisa, foram significativos, pois com o descobrimento desses perfis empreendedores, permitese salientar a importância da incubadora de empresas no campus. Sabe-se que a incubadora de empresas possibilitará aos discentes, a oportunidade de desenvolverem suas características empreendedoras e com isso obterem sucesso como empreendedores.

Fundamentado nas análises feitas, os resultados obtidos mostraram que o maior perfil encontrado nos discentes foi o empreendedor em desenvolvimento, o que de certo modo, mostra que os discentes possuem perfil empreendedor, porém como ressaltado anteriormente, precisam aperfeiçoar os pontos fracos para passarem a ser empreendedores natos. Contudo, esse resultado possibilita que com a implantação da incubadora de empresas no campus São Gonçalo do Amarante, os discentes podem desfrutar dos inúmeros benefícios que esta traz para o empreendedor e seria de grande valia para estimular e apoiar os discentes a serem empreendedores de sucesso, por meio de todo amparo e capacitação.

É importante salientar, ainda, que a incubadora de empresas contribuiria com o crescimento econômico regional, o que é para o município, um fator importante, visto que com a implantação desse habitat de inovação e com os projetos dos discentes, possibilitará uma maior visibilidade tanto para as empresas incubadas, quanto para o instituto federal. Dessa maneira, a partir dos projetos inovadores aprovados, tanto a academia ganharia quanto o munícipio, por meio de vantagens econômicas.

Conjuntamente, vale-se a ideia de futuras pesquisas que estudem mais características empreendedoras dos discentes, uma vez que percebeu-se que dentro das estruturas acadêmicas, existem muitos empreendedores escondidos, que com a ajuda das incubadoras, podem ser lapidados para serem futuros empreendedores de sucesso.

\section{REFERÊNCIAS}

ANDRADE, Claudia Cristina et al. Análise do capital institucional na incubadora de empresas de base tecnológica: um estudo de caso no município de Itajubá-MG. Revista de Administração, Contabilidade e Economia da Fundace, v. 7, n. 1, 2016.

AGUIAR, Alessandra de Oliveira; MARTINS, Marina Soares Sabioni. Empreendedorismo jovem na comunicação: um guia de criação e gestão de um negócio na área de comunicação organizacional. 2015.

CARLAND, JoAnn C.; CARLAND, James W.; STEWART, Wayne H. Seeing what's not there: The enigma of entrepreneurship. Journal of small business strategy, v. 7, n. 1, p. 1-20, 2015. 
CRECENTE-ROMERO, Fernando; GIMÉNEZ-BALDAZO, Mónica; RIVERA-GALICIA, Luis F. Subjective perception of entrepreneurship. Differences among countries. Journal of Business Research, 2016.

DEVECE, Carlos; PERIS-ORTIZ, Marta; RUEDA-ARMENGOT, Carlos. Entrepreneurship during economic crisis: Success factors and paths to failure. Journal of Business Research, 2016.

DORNELAS, José Carlos de Assis. Empreendedorismo: transformando ideias em negócios: $3^{\mathrm{a}}$ ed. Rio de Janeiro: Editora Elsevier, 2008.

FRANCISCO, THIAGO HENRIQUE ALMINO et al. A CONTRIBUIÇÃO DAS RELAÇÕES DA TRÍPLICE-HÉLICE NO FOMENTO AOS PROJETOS DE EXTENSÃO: UMA ANÁLISE DAS AÇÕES DE UMA UNIVERSIDADE COMUNITÁRIA. 2015.

FÉLIX, Carlos Alonso Hernández; GUTIÉRREZ, MA Rosa del Carmen Caballero; BURBOA, MA Georgina Castro. INCUBADORAS DE EMPRESAS. 2013.

GEM, Global Entrepreneurship Monitor. Empreendedorismo no Brasil: Relatório Executivo. Curitiba: Sebrae. Disponível em: https://www.sebrae.com.br/Sebrae/Portal\%20Sebrae/Estudos\%20 e\%20Pesquisas/gem\%202014_relat\%C3\%B3rio\%20executivo.pdf. Acesso em 25/11/2016, v. 9, 2014.

GIL, Antonio Carlos. Como elaborar projetos de pesquisa. São Paulo, v. 5, p. 61, 2002.

KAUARK, F. da S.; MANHÃES, Fernanda Castro; MEDEIROS, Carlos Henrique. Metodologia da pesquisa: um guia prático. Itabuna: Via Litterarum, v. 18, 2010.

Lei no 10.973/04. Lei no 10.973/04 de 2 de dezembro de 2004. Presidência da República. Casa civil, subchefia de assuntos jurídicos.

MAS-VERDÚ, Francisco; RIBEIRO-SORIANO, Domingo; ROIG-TIERNO, Norat. Firm survival: The role of incubators and business characteristics.Journal of Business Research, v. 68, n. 4, p. 793-796, 2015.

PADULA, Camila Nathália; DA SILVA, Djalma Donizetti Clariano; JUNIOR, José Marques Pereira. A RELEVÂNCIA DOS ARRANJOS COLABORATIVOS NO FORMATO DE TRIPLICE HÉLICE QUE COLABORAM COM A INOVAÇÃO DAS MPE' s E SEUS DESDOBRAMENTOS NOS ASPECTOS OPERACIONAIS, GESTÃO E SÓCIOECONÔMICO. Revista FATEC Sebrae em debate: gestão, tecnologias e negócios., v. 3, n. 4, p. 142, 2016. 
PEREIRA, Jaiane Aparecida et al. DESENVOLVIMENTO DE ESTRATÉGIAS DE ESTÍMULO A EMPRESAS INCUBADAS DE BASE TECNOLÓGICA: UM ESTUDO MULTICASO EM INCUBADORAS DO ESTADO DO PARANÁ. Latin American Journal of Business Management, v. 6, n. 3, 2015.

PERUCCHI, Valmira. Produção de conhecimento científico e tecnológico nos Institutos Federais de Educação, Ciência e Tecnologia: uma investigação sobre a sua natureza, divulgação e aplicação. 2015.

RIBEIRO, Ana Regina Bezerra et al. FATORES QUE CONTRIBUEM PARA O SUCESSO DE EMPRESAS DE BASE TECNOLÓGICA: UM ESTUDO MULTICASOS EM INCUBADORAS DE PERNAMBUCO. Revista Eletrônica de Estratégia \& Negócios, v. 9, n. 2, p. 208-233, 2016.

MARTELO, Marcelo Ricardo; CLARO, José Alberto Carvalho Dos Santos; VIEIRA, Almir Martins. Clima Organizacional No Contexto De Uma Incubadora: Estudo Com Três Empreendimentos Do Interior De São Paulo. Revista FSA, v. 13, n. 2, 2016.

SANTOS, Ana Paula Silva dos. Processo de gestão do conhecimento como fator-chave na estruturação do Núcleo de Inovação Tecnológica nas universidades. 2016.

Serviço Brasileiro de Apoio às Micro e Pequenas Empresas. Sobrevivência das empresas no Brasil- 2016. [Online] Disponivel da Internet via: http://www.sebrae.com.br/Sebrae/Portal\%20Sebrae/ Anexos/sobrevivencia-das-empresas-no-brasil-relatorio-2016.pdf. Arquivo capturado em 03/05/2017.

STANIEWSKI, Marcin W. The contribution of business experience and knowledge to successful entrepreneurship. Journal of Business Research, 2016.

STOKAN, Eric; THOMPSON, Lyke; MAHU, Robert J. Testing the Differential Effect of Business Incubators on Firm Growth. Economic Development Quarterly, p. 0891242415597065, 2015.

VERLINDE, Sara; MACHARIS, Cathy. Innovation in Urban Freight Transport: The Triple Helix Model. Transportation Research Procedia, v. 14, p. 1250-1259, 2016.

WANG, Yi-Shun et al. What drives students' cyber entrepreneurial intention: The moderating role of disciplinary difference. Thinking Skills and Creativity, v. 22, p. 22-35, 2016.

WONGLIMPIYARAT, Jarunee. The innovation incubator, university business incubator and technology transfer strategy: The case of Thailand.Technology in Society, v. 46, p. 18-27, 2016.

YIN, Robert K. Estudo de Caso-: Planejamento e Métodos. Bookman editora, 2001. 